\title{
Ekplanasi IImiah Metode Hipnotis terhadap Otak Manusia
}

\author{
Muhyiatul Fadilah \\ Universitas Negeri Padang, Padang, Indonesia \\ e-mail: muhyiid.mf@gmail.com
}

\begin{abstract}
Hypnotic is a method to explore humans' conscious mind in order to experience suggestion alteration following particular purpose. Previously, in Indonesia, hypnotic was dominantly known as one on crimes technique to rob the victims easily in short time. Then, public perception shifted after hypnotic action performed in stages to entertaintaudience. Recently, hypnotic has been applied to benefit patient, students or individual with biological and psychological pains. Unfortunately, the existence of hypnotic as a logical explanation have not been available in a comprehensible text for public understanding, although excessive empirical studies existed in multidiscipline ways. This review article propose a scientific explanation toward hypnotic and its application such medical and educational purposes, based on a scientific philosophy. To conclude, hypnotic concept developed according to DeductiveNomologies Explanation Scientific Model and fulfill positivistic and naturalistic truth paradigm and pragmatic truth theory. Its brief scientific explanation that is hypnotic processes with support of brain structure and mechanism. Scientific terms and concepts which are been involved are cerebrum, autonomous nervous system, reticular activating system, medulla oblongata, brainstem, corpus collosum, brain wave frequencies alteration, and chemically control of serotonine and endorphin.
\end{abstract}

Keyword: hypnotic, brain anatomy and wave frequency, explanation, science philosophy

\section{Pendahuluan}

Hipnotis dipahami sebagai salah satu carauntuk menghilangkan kesadaran seseorang sehingga korban hipnotis dapat dikendalikan oleh pelaku hipnotis dan sewaktu-waktu dapat dikembalikan ke posisi kesadaran seperti semula. Di Indonesia, masyarakat awam umumnya memiliki pandangan negative terhadap kata hipnotis karena metode hipnotis sering diberitakan sebagai salah satu cara pelaku kejahatan untuk mendapatkan benda atau target kejahatan yang diincar pada korban. Banyak media mengekspos kasus kejahatan melalui metode hipnotis dapat menimbulkan kerugian finansial yang sangat besar dalam waktu yang sangat singkat tanpa adanya bukti kekerasan atau bukti fisik lainnya pada korban, sehingga pelaku kejahatan dengan teknik hipnotis sulit dilacak. Sehingga, muncul asumsi bahwa hipnotis berasosiasi dengan ilmu mistik tertentu (Putra, 2010).

Pemahaman masyarakat terhadap teknik hipnotis mulai beragam melalui aksi panggung hipnotis yang ditayangkan di televisi, dalam program bertemakan sulap atau magic, baik yang ditampilkan oleh pesulap terkenal dunia, ataupun pesulap Indonesia, seperti Romy Rafael. Penampilan hipnotis dalam sulap memukau perhatian penonton dan memberikan efek hiburan sehingga secara perlahan terjadi pergeseran asumsi dari hipnotis yang menakutkan menjadi hipnotis yang menakjubkan. Aksi panggung hipnotis memberikan pemahaman bahwa seseorang bisa menghilangkan kesadaran orang lain dengan terencana.

Praktek hipnotis semakin menawarkan efek hiburan melalui salah satu tayangan reality showdi salah satu stasiun televise swasta, yang dipopularkan oleh actor seni bernama Uya Kuya. Belakangan, metode hipnotis diaplikasikan pada bidang-bidang yang lebih memiliki nilai positif seperti bidang pengobatan medis, kejiwaan, pendidikan dan teknik hafal AIQuran. Hal ini seiring dengan perkembangan kajian hipnosisme di dunia barat, yang mengapresiasi kajian hypnosis secara ilmiah pada tingkat doctoral, seperti pada beberapa universitas di Amerika.

Aplikasi metode hipnotis yang semakin meluas mulai mereduksi paradigma negative metode hipnotis, namun belum memberikan penjelasan ilmiah yang logis dan rasional serta bisa dipahami oleh masyarakat awam. Latar belakang perkembangan metode hipnotis yang mengadopsi kekuatan salah satu dewa di zaman Yunani, Dewa Hypno atau Dewa Tidur, telah 
memposisikan hipnotis sebagai pengetahuan yang bersumber dari faith atau keyakinan dalam bentuk, dan sebagai bagian dari system kepercayaan (beliefs), serta memelukan verifikasi ilmiah agar dapat diterima kebenarannya (Soetriono \& Hanafie, 2007 dalam Firman, 2018).

Artikel ini bertujuan untuk memberikan eksplanasi ilmiah metode hipnotis sebagai suatu produk dari penalaran ilmiah dalam pandangan filsafat sains. Dengan demikian, aplikasi hipnotis dapat lebih dikaitkan dengan konteks-konteks yang lebih positif dan memberikan manfaat dalam kehidupan karena diakui sebagai bagian struktur ilmu yang rasional dan logis.

\section{Metode}

Artikel ini merupakan kajian ulas balik (review) yang menggunakan pendekatan studi kepustakaan (library research) melalui penelaahan terhadap buku-buku, literatur-literatur, dan artikel ilmiah terkait. Selain itu, hasil-hasil penelitian empiric digunakan sebagai data sekunder untuk memperkuat argumentasi yang kemudian disintesis hingga menjadi kesatuan dalam memberikan informasi.

\section{Hasil dan Pembahasan}

Hipnotis

Hipnotis adalah salah satu cara untuk mengekplorasi fikiran bawah sadar. Hipnotis berasal dari bahasa yunani yang berarti tidur. Hipnosis merupakan istilah yang lazim dipakai dalam praktek, sedangkan dalam kajian keilmuan digunakan hypnosis. Istilah hypnosis diperkenalkan oleh James Braids pada 1943 dengan arti yang lebih dalam, yaitu "neurohipnosis, yang berarti 'tidur dari system saraf'. Seseorang yang sedang berada dalam kondisi hypnosis, akan lebih mudah menerima saran atau sugesti (Hyper-sugestion) (Hakim, 2010).

Martin Orne mendefinisikan hipnotis sebagai keadaan atau kondisi dimana orang mampu berespon terhadap sugesti yang sesuai dengan mengalami perubahan persepsi daya ingat atau mood. Ciri penting dari hipnotis adalah perubahan pengalaman subyektif (Kaplan \&Sadock, 2002). Departemen Pendidikan Amerika Serikat mendefinisikan hipnotis "hypnosis is the bypass of the critical factor of the conscious mind followed by the establishment acceptable selective thinking" atau "hipnosis adalah penembusan faktor kiritis pikiran sadar diikuti dengan diterimanya suatu pemikiran selektif/sugesti." (Kahija, 2007). Individu yang terhipnotis menjadi responsif terhadap pengaruh orang yang menghipnosis, dapat mengingat kembali kejadiankejadian yang telah dilupakan serta dapat meredakan gejala psikologisKorban hipnotis tetap mampu berkomunikasi sebagai bukti bahwa hipnotis tetap memungkinkan seseorang melakukan interaksi social, bertindak untuk mengalami pengalaman imajinatif yang melibatkan perubahan kognisi.

\section{Struktur Otak dalam Kajian Biologi}

Secara anatomi, otak (brain) terdiri atas bagian otak besar (cerebrum), otak kecil (cerebellum) dan batang otak (brain stem). Otak besar memiliki 4 lobus, yaitu (1)Lobus Frontal, terletak di depan dan berfungsi berfungsi mengatur kegiatan motoric sadar, kemampuan bicara, kemampuan berfikir dan emosi, (2) Lobus Parietal, terletak dibelakang belakang lobus frontal, merupakan pusat sensorik, (3) Lobus Temporal, terletak dibawah lobus parietal, lebih tepatnya dibagian sisi otak besar, berfungsi sebagai pusat pendengaran dan bahasa, dan (4)Lobus Oksipital, bagian belakang yang memiliki fungsi utama sebagai pusat penglihatan (Campbell, 2014).

Otak kecil berada dibawah otak besar bagian belakang dan berfungsi untuk koordinasi gerakan otot, mempertahankan postur berdiri dan keseimbangan. Batang otak merupakan bagian pusat relay yang menghubungkan otak besar dan otak kecil dengan sumsum tulang belakang. Batang otak memiliki fungsi mengatur proses otomatis seperti bernapas, denyut jantung, suhu tubuh, siklus bangun dan tidur, pencernaan, bersin, batuk, muntah, dan menelan.

Struktur anatomi otak terbentang secara lateral pada belahan kanan dan kiri. Otak besar belahan kanan bekerja mengatur aktivitas tubuh bagian kiri, sebaliknya otak besar belahan kiri mengatur aktivitas tubuh bagian kanan. Otak hemisfer kiri dan kanan dihubungkan oleh Corpus Collosum yang yang berfungsi menyampaikan pesan dari satu sisi ke sisi lainnya (Raven \& Johnson, 2009)

Pembagian belahan otak kiri dan kanan juga dikaji secara fungsi mentalnya dalam sebuah teori, yaitu Teori Otak Kiri dan Otak Kanan yang dikembangkan Sperry (Putra, 2010). Secara garis besar, kedua belahan tersebut memiliki fungsi yang berbeda-beda. Otak kanan 
(otak kreatif) berhubungan dengan proses dan penyimpanan informasi mengenai gambar, imajinasi, warna, dan ritme. Sementara otak kiri (otak analitis) berhubungan dengan angkaangka, kata-kata, logika, dan detail (Bahauddin, 1999 dalam Zulkaida, Dewi, Prabowo, 2005).

Pembagian otak atas hemisfer kiri dan kanan berkaitan dengan fungsi otak dalam mengendalikan aktivitas kognitif atau mental. Sejalan dengan hal tersebut, Teori kuadran yang dikembangkan oleh Hermann membagi otak dalam empat kuadran yang memberikan gambaran yang lebih sempuma dalam memahami kecenderungan perilaku seseorang (Putra, 2010).

\section{Kajian Fisika dan Kimia menjelaskan Mekanisme Kerja Otak}

Jaringan otak manusia hidup menghasilkan gelombang listrik yang berfluktuasi yang disebut brainwave atau gelombang otak. Gelombang otak menandakan aktifitas pikiran seseorang (Rusli \&Wijaya, 2009). Otak adalah organ tubuh bersifat elektrokimia yang dispekulasi dapat menghasilkan energi listrik sebesar 10 watt. Sejumlah peneliti terdahulu pernah mengkalkulasi jika seluruh 10 milyar sel syaraf manusia bisa disambung menjadi satu, maka elektroda pengukur akan mencatat angka seperlimajuta hingga seperlimapuluhjuta volt.

Gelombang otak diukur dengan alat yang dinamakan Electro Encephalograph (EEG) yang ditemukan pada tahun 1929 oleh psikiater Jerman, Hans Berger. Hasil pengukuran menginformasikan empat gelombang otak yang diproduksi oleh umumnya otak manusia yaitu Beta, Alpha, tetha, Delta. Menurut Ellias (2009), kondisi Beta, Alpha, dan Theta, merupakan kondisi umum yang berlangsung secara bergantian dalam diri kita. Suatu saat kita di kondisi Beta, kemudian sekian detik kita berpindah ke Alpha, sekian detik berpindah ke Theta, dan kembali lagi ke Beta, dan seterusnya.

Setiap gelombang otak memiliki perbedaan frekuensi, kecepatan gelombang, dan fungsi. Gelombang Betamemiliki frekuensi $13-40 \mathrm{~Hz}$. Gelombang Betatinggi merangsang otak mengeluarkan hormon kortisol dan norepinefrin yang menyebabkan cemas, khawatir, marah, dan stress. Alpha merupakan gelombang berfrekuensi 8-13 Hz. Manfaat utama alfa adalah sebagai jembatan penghubung pikiran sadar dan pikiran bawah sadar. Gelombang Theta memiliki frekuensi 4-7 Hz. Thetaberhubungan dengan kondisi relaksasi yang sangat ekstrim. Terakhir, Delta memiliki frekuensi gelombang otak kecil dari 0,5-4 Hz (Raven \& Johnson, ).

Kondisi Delta diperlukan oleh tubuh agar sel tubuh memiliki kesempatan untuk melakukan melakukan peremajaan terhadap sel-sel tubuh, memperbaiki kerusakan jaringan dan aktif memproduksi sel-sel baru. Di gelombang ini otak mengeluarkan Human Growth Hormone (hormon pertumbuhan)

Gelombang Alpha dan Theta adalah gelombang pikiran bawah sadar.Pada kondisi Alpha, anggota tubuh masih bisa dirasakan karena otak mengeluarkan hormon melatonin, catecholamine dan AVP (Arginine vasopressin).

\section{Mekanisme Sistem Otak dalam Proses Hipnotis}

Hasil penelitian telah menginformasikan bagaimana mekanisme otak mampu menjelaskan atensi, control motoric, percepsi sedih, kepercayaan dan kemauan (Oakley \& Halligan, 2013), termasuk potensinya untuk menjelaskan hipnotis. Kajian keterlibatan otak dalam menjelaskan hipnotis relevan dengan pandangan Freudianisme. Freud adalah seorang pemikir abad kedua puluh yang melakukan revolusi tentang pemahaman hakikat manusia yang mendalami psikoanalisa. Freud mengemukakan pandangan yang kontroversial terhadap gagasan mainstream psikologi strukturalis, bahwa pemikiran dan kesadaran sebagai aspek utama dari kehidupan kejiawaan.

Namun demikian, salah satu asumsi Freud bertentangan dengan kajian ilmu neurosains. Neurosains merupakan studi ilmiah tentang komponen biofisik yang berkaitan dengan kognisi, afeksi, dan sosial yang menggunakan pendekatan interdisiplin antara psikologi kognitif, neurosains, artificial intelligence, dan biologi.

Freud menyatakan bahwa kondisi kejiwaan berbeda dengan kondisi fisiologis, dan tidak menyetujui dualisme dua substansi jiwa dan tubuh (Hutapea, 2011), sementara menurut ilmu neurosains, terdapat mekanisme sinergis antara struktur-struktur yang membangun unsur manusia sebagai objek fisik dan subjek kejiwaan.

Dualism jiwa dan tubuh Freud yang dapat dijelaskan secara ilmiah. Oakley dan Halligan (2013) menjelaskan adanya keterlibatan system korteks frontal dalam memediasi respon menuju sugesti dan pengalaman yang mengiringi ketidaksadaran. Korteks merupakan lapisan terluar substansi abu-abu (gray material) dari otak besar (cerebrum). Lapisan ini memiliki memiliki ketebalan beberapa millimeter saja, namun mengandung lebih dari 10 milyar sel saraf, sekitar $10 \%$ dari jumlah sel saraf dalam otak. Lapisan tersebut berlekuk kedalam sehinggan memiliki luas permukaan yang relative besar (Raven \& Johnson, 2009). 
Pikiran (mind) merupakan target hypnosis yang dijelaskan oleh eksistensi otak (brain) secara biologis, meliputi struktur tingkat sel dan jaringan otak dalam system saraf. Otak merupakan sistem pikiran manusia terdiri atas 3 (tiga) yaitu alam sadar, alam bawah sadar dan alam tidak sadar(Kahija, 2007).Pikiran Sadar atau Conscious Mind (CM), merupakan sisi logis, analitis, kritis dan rasional, biasanya diasosiasikan dengan otak kiri. Secara singkat, CM adalah sistem yang dipakai jika sedang berpikir apapun, bersifat terfokus dan memiliki kapasitas yang terbatas. Pikiran sadar umumnya hanya bisa berpikir satu dua hal saja secara sekaligus, dan maksimumnya adalah tujuh buah ide bersamaan Pikiran Bawah Sadaratau Subconscious Mind (SM), merupakan letak dari memori, memiliki sifat "netral", dan juga menampung berbagai program-program seperti sistem keyakinan (belief system), citra diri (self image), dan biasanya diasosiasikan dengan otak kanan. Terakhir, pikiran tak sadar atau Unconscious Mind (UM) merupakan sistem yang mengontrol fungsi tubuh yang sama sekali berada diluar kendali kita, seperti pernafasan, kekebalan tubuh, kedipan mata, detak jantung, pencernaan lambung, dsb. Pikiran sadar menempati 12 persen dari kemampuan otak, 88 persen, disebut alam bawah sadar (subconsious).

Ketika pikiran sadar terbentuk dan berkembang, biasanya mulai usia 3 tahun, terciptalah suatu pintu pembatas antara pikiran sadar dan pikiran bawah sadar. Hipnosis membuka pintu pembatas tersebut dengan membuat sibuk (Prihatanto, 2008) atau focus terhadap stimulus audio/visual (Putra, 2010). Pikiran sadar yang berada pada wilayah korteks akan mengalami istirahat dan frekuensi gelombang otak akan bergeser dari kondisi Beta ke kondisi Alfa atau Tetha, menuju pikiran bawah sadar, pada bagian medulla oblongata.

Dalam kondisi Alpha, seseorang yang mengalami relaksasi. Kroger (2008) menyatakan keadaan Alpha diasosiasikan dengan menutup mata, istirahat atau melamun. Balita selalu berada dalam kondisi Alpha sehingga umumnya mampu menyerap informasi dengan cepat.

Dalam kondisi gelombang ini, otak memproduksi hormon serotonin dan endorfin yang menyebabkan seseorang merasa tenang, nyaman dan bahagia. Gelombang Alphaakan membuat imunitas tubuh meningkat, pembuluh darah terbuka lebar, detak jantung menjadi stabil, dan kapasitas indra kita meningkat.

Individu yang diberikan hipnotis, gelombang pikirannya masuk ke gelombang alfa atau lebih dalam lagi ke gelombang Theta. Ketika pikiran masuk ke gelombang ini, sistem metabolisme tubuh menjadi jauh lebih baik dan tubuh bebas dari ketegangan (Hastuti dan Ayumsari, 2015). Hal ini sesuai dengan salah satu teori hipnotis yaitu Teori tidur yang dikondisikan, yaitu hipnotis terjadi dalam Keadaan Alfa dan Theta (Putra, 2010).

Saat seseorang dihipnotis, System korteks frontal memediasi mulai dari respon hingga sugesti yang menyertai kondisi seseorang dalam keadaan tidak sadar (Raven \& Johnson, 2009). Pikiran sadar yang berada pada wilayah korteks akan mengalami istirahat dan frekuensi gelombang otak akan bergeser dari kondisi Beta ke kondisi Alfa atau Tetha, menuju pikiran bawah sadar, pada bagian medulla oblongata. Pemindahan wilayah pikiran dari kesadaran menuju alam bawah sadar melalui hipnotis berasosiasi dengan pengaktifan saraf parasimpatis. sehinggasubjek menjadi sangat rileks dan nyaman (IBH, 2002). Saraf parasimpatik merupakan bagian dari system saraf otonom yang mengatur sistem internal dan gerak diluar kesadaran (Campbell, 2014).

Agar sugesti masuk ke pikiran sadar, maka perlu pengurangan aktivitas bagian otak yang bernama Critical Area. Critical Area adalah penampungan data sementara, dimana di tempat inilah data akan diproses berdasarkan analisa, logika, pertimbangan etika, dan lain-lain. Keaktifan critical area berbeda-beda untuk setiap situasi dan kondisi, tergantung dari fokus, minat, dan emosi. Secara alamiah, critical area akan terbuka pada saat kita sedang rileks, fokus terhadap sesuatu, berminat yang tinggi terhadap sesuatu, atau kepercayaan yang tinggi. Seorang Hipnotis memiliki keterampilan untuk membuat critical area berkurang keaktifannya, sehingga bisa memerintah dan masuk ke pikiran bawah sadar orang lain melalui stimulus suara.

Critical Area dalam dunia medis dikenal sebagai RAS (Reticular activating system). Raven \& Johnson (2009) menjelaskan bahwa RAS terlibat dalam pembentukan formasi retikuler (reticular formation), yaitu suatu kumpulan sel saraf pada otak tengah (midbrain), pons, dan medulla oblongata, yang dikenal dengan istilah batang otak (brainstem).RAS mengontrol kesadaran dan keterjagaan. Semua jalur sensorik masuk ke RAS, yang memonitor informasi yang masuk ke otak dan mengidentifikasi stimulus penting. Selain itu, RAS berfungsi menentukan apa yang menjadi fokus perhatian, menentukan seberapa besar tingkat intensitas perhatian, dan berapa lama perhatian itu diberikan (Gunawan, 2005). 
Hipnotis merupakan salah satu cara untuk melewati filter RAS menuju pikiran bawah sadar. Filter ini terbuka luas dipengaruhi oleh kondisi gelombang otak, pemikiran, dan emosi. Selain itu Filter RAS berfungsi sebagai pengaman untuk menyaring pikiran dan perilaku baru. Filter membandingkan informasi baru dengan kepercayaan yang ada dalam pikiran bawah sadar. Hal itu bertujuan agar pikiran bawah sadar tidak selalu berubah dan tidak mudah dipengaruhi sugesti dari luar.

Hipnotis mempersyaratkan kesediaan seseorang untuk mau menerima sugesti. Sebagian orang, sulit menerima sugesti. Menurut IBH (2002), orang yang memiliki kondisi kejiwaan yang relatif tenang atau terbiasa berkonsentrasi ke internal, cenderung untuk lebih mudah memasuki Hipnotic State. Hasil penelitian James E. Horton dari University of Virginia's College di Wise dan Helen J Crawford dari Virginia Polytechnic Institue and State University menunjukkan melalui citra MRI (Magnetic Resonance Image) bahwa bagian rostrum dari corpus callosum berukuran $32 \%$ lebih besar pada individu yang mudah mengalami hypnosis dibandingkan pada subjek yang relative sulit mengalami hypnosis (Putra, 2010). Luders, Steinmetz \& Jancke (2002) melaporkan dari sejumlah tulisan bahwa area corpus callosum (CC) pada wanita relative lebih besar, sehingga pelintasan midline oleh akson interhemisfer juga lebih besar .

Corpus Collosum merupakan bagian yang menghubungkan hemisfer kiri dan kanan otak (Campbell, 2014) sehingga memungkinkan pertukaran informasi meskipun awalnya hanya satu belahan yang menerima informasi (Springer et al, dalam Zillmerr, 2008). Fungsi ini didukung oleh kandungan 190 juta akson myelin pada corpus Collosum (Paul, et al. 2014). Lebih lanjut, Putra (2010) menjelaskan bahwa rostrum pada corpus collosum memainkan peranan dalam mengalokasikan atensi dan penghambatan stimulus yang tidak diinginkan.

Bukti empiris mekanisme system otak dalam hipnotis dipresentasikan oleh Huber et al. (2013). Huber et al. menemukan bahwa hypnotic suggestibility berkorelasi positif dengan volme substansi abu-abu pada bagian superior kiri dan frontal tengan dari girus bertumpang tindih dengan area motor presuplementer dan suplementer dan berkorelasi negative dengan volume substansi abu-abu dalam insula dan girus lobus temporal superior kiri. Jika dikaji dalam konektivitas fungsional antara area posterior tengah (termasuk korteks singulat posterior dan precuneus) dengan kedua jaringan visual lateral dan jaringan fronto-parietal bagian kiri, juga terdapat korelasi positif antara jaringan control eksekutif dan area postcentral/parietal kanan. Temuan Hoeft et al. (2012) membuktikan bahwa hipnotis dapat diatur dengan merubah konektivitas fungsional dalam korteks prefrontal dorsolateral dan korteks singulat anterior dorsal.

Proses hipnotis diakhiri dengan pemberian sugesti agar subjek tidak mengalami kejutan psikologis ketika terbangun dari tidur hypnosis. Hal ini juga melibatkan pengembalian fungsi RAS, karena system ini mengendalikan fungsi tidur dan bangun (Raven \& Johnson, 2009 ). Biasanya dilakukan dengan membangun sugesti yang positif yang akan membuat tubuh subjek lebih segar dan rileks kemudian diikuti beberapa regresi selama beberapa detik untuk membawa subjek ke keadaan normal kembali (IBH, 2002).

\section{Pandangan Filsafat Sains Terhadap Hipnotis}

Paparan empiris tentang keterlibatan system otak dan mekanisme otak dalam sudut pandang Fisika, Kimia, dan Biologi telah menunjukkan bahwa secara epistemologi, pengetahuan hipnotis telah berkembang mengikuti metode ilmiah. Hipnotis pada awalnya dipandang sebagai salah bentuk kepercayaan (beliefs) dan kemampuan intuisi (Hakim, 2010). Pengetahuan ini termasuk pengetahuan metafisis yang berkembang melalui realitas. Plato dan Hegel menganggap realitas metafisika merupakan dasar dari semua realitas (Lubis, 2016). Namun, dalam pandangan filsafat sains, realitas metafisik membutuhkan interpretasi yang logis, teramati, terstruktur dan empiris agar bisa menempati struktur pengetahuan ilmiah. M, Gold Stein dan I.F Goldstein dalam Sudarmin (2016) mengemukakan aktivitas penelusuran sebagai penanda aktivitas sains. Suatu realitas memerlukan penelusuran untuk mencapai pengertian dan memperoleh pemahaman.

Pengetahuan hipnotis berkembang mengikuti pola eksplanasi ilmiah model HempelOppenheim atau Model Deductive Nomologis (Model D-N). Deduksi merupakan proses penalaran yang bertolak dari generalisasi (Lubis, 2016). Firman (2018) menyatakan bahwa ada 3 (tiga) kondisi logis yang menjadi syarat eksplanasi ilmiah model D-N; (1) eksplanandum (perkara yang dijelaskan) diturunkan dari eksplanan-eksplanan (perkara yang menjelaskan), (2) deduksi harus menggunakan hukum umum, dan 3) eksplanan-eksplanan harus mempunyai konten empiris.

Sebagai sebuah deduksi, konsep hipnotis telah terbangun sejak awal perkembangan ilmu hipnotis, yaitu upaya menimbulkan kenyamanan melalui sugesti pikiran. Konsep hipnotis yang 
diterima pada abad 21 saat ini merupakan eksplanandum melalui 2 eksplanan yang mendominasi, yaitu eksplanan struktur dan fungsi otak yang terintegrasi dalam pandangan Biologi, Fisika, dan Kimia. Eksplanan struktur dominan dijelaskan dalam kajian Biologi, melalui adopsi dan adaptasi perkembangan dan spesifikasi ilmu, yaitu neurologi dan neurosains. Eksplanan fungsi otak didukung oleh penjelasan Fisika yang mengintegrasikan kajian gelombang dan pembentukan potensial listrik pada impuls saraf di otak. System hormone merupakan kajian Kimia yang menjelaskan substansi dan mekanisme kimiawi yang mengatur dan mengizinkan proses fisis dan fisiologi otak berjalan semestinya.

Dalam pemanfaatannya, eksplorasi pikiran bawah sadar diarahkan untuk memprogram ulang pikiran bawah sadar untuk berbagai tujuan positif dengan memberikan memori, saran atau sugesti, sehingga seseorang dapat diberikan memori, saran, atau sugesti yang dapat memprogram ulang pikiran bawah sadarnya untuk berbagai tujuan positif. Fachry (2008) mengemukakan bahwa pikiran manusia terdiri dari program-program yang diinstall ke dalamnya, dimana pemrograman ini dimulai sejak masa kanak-kanak khususnya lima tahun pertama sehingga cukup berpengaruh dalam kehidupan seseorang di masa-masa berikutnya. Oleh karena itu bisa ditebak bagaimana pengaruh program positif atau negatif yang sudah terinstall dalam pikiran. Menariknya program-program tersebut mirip komputer bisa diganti atau diubah dengan program baru. Salah satunya dengan mengakses bawah sadar melalui hipnosis. Oleh sebab itu hipnosis bisa digunakan untuk terapi yaitu memrogram ulang pikiran dengan caramengganti program negatif menjadi program positif. Rusli\& Wijaya (2009) menjelaskan bahwa hipnosis bekerja untuk memberikan nilai-nilai baru pada seseorang yang akhirnya akan berdampak pada perubahan pola pikir maupun tindakan seseorang yang telah menjalani proses hypnosis.

Perkembangan studi empiris yang memberikan skplanasi ilmiah hipnotis menunjukkan proses perolehan menuju kriteria kebenaran hipnotis sebagai ilmu. Dalam kajian filsafat, Sudarmin (2016) mengemukakan 4 (empat) paradigm dalam mencari kebenaran, yaitu paradigm kebenaran atas logika, paradigm positivistic atau paradigm sains, paradigm naturalistic dan paradigm modus operandi. Paradigm kebenaran atas logika mencirikan kebenaran jika ada konsistensi dengan aksioma-aksioma serta definisi yang berlaku. Berbeda dengan 3 (tiga) paradigm lainnya, yang menekankan pada pentingnya kegiatan empiris berupa eksperimen untuk paradigm sains, studi lapangan untuk paradigm naturalistic, pengujian dan penelitian secara periodic untuk paradigm modus operandi. Berdasarkan penjelasan tersebut, kebenaran hipnotis sebagai suatu ilmu diperoleh sesuai dengan paradigm positivistic dan naturalistic karena memiliki bukti berlimpah yang telah dibuktikan dalam penelitian multidisiplin.

Hipnotis juga memenuhi kriteria kebenaran lainnya, yang berasosiasi dengan aplikasi meluas hipnotis dalam berbagai bidang, seperti kesehatan, psikologi dan pendidikan. Dalam bidang pengobatan, hipnotis dengan hipnoterapi, yang digunakan untuk terapi rasa nyeri, alcohol atau proses kelahiran (hypnobirthing). Untuk pengobatan, diperlukan keadaan Theta (Kroger, 2008). Keadaan Theta dikaitkan dengan hipnosis untuk pembedahan, hipnoanestesia (penggunaan hipnotis untuk mematirasakan rasa sakit), dan hipnoanalgesia (penggunaan hipnotis untuk mengurangi kepekaan terhadap rasa sakit), di mana pembedahan lebih siap dilakukan dalam keadaan Theta dan Delta. Obat bius (anestetik), zat penenang (sedatif) dan hipnotis mengacaukan keselarasan syaraf, yang dianggap mendasari terjadinya gelombang Theta, baik pada manusia maupun binatang.

Dalam bidang pendidikan, dikenal istilah hypnoteaching, yang terbukti efektif digunakan untuk meningkatkan motivasi, sikap dan memori siswa dalam belajar. Hipnotis telah dipraktekan untuk mengurangi kecemasan (anxiety) mahasiswa menghadapi masalah akademik. Hastuti dan Arumsari (2015) membuktikan bahwa teknik hipnotis limajari berpengaruh signifikan dalam penurunan anxiety mahasiswa di STIKES Muhammadiyah Klaten.

Hasil-hasil riset terbaru pada bidang tersebut telah memperkuat kebenaran hipnotis akibat nilai manfaat yang diberikan terhadap manusia. Berdasarkan tren tersebut, hipnotis menjadi ilmu yang memenuhi teori kebenaran pragmatism, yaitu suatu kebenaran yang diterima berdasarkan sifat fungsionalnya dalam kehidupan praktis (Firman, 2018).

\section{Simpulan}

Hipnotis merupakan suatu metode untuk mengeksplorasi pikiran bawah sadar agar individu tertentu dapat mengalamai peningkatan sugesti sesuai dengan tujuan yang diinginkan terhadap individu tersebut. Hipnotis dapat dijelaskan dengan melalui mekanisme otak dalam kajian biologi, fisika dan kimia. Bagian otak yang berperan dalam hipnotis adalah otak besar 
(cerebrum), Reticular Activating System (RAS), saraf parasimpatis, medulla oblongata dan corpus collosum. Sinergisme fungsi dari bagian ini berasosiasi dengan perubahan frekuensi gelombang otak Betha menjadi Alpha dan Theta serta pelepasan hormone serotonin dan endorfin.

Dalam kajian filsafat sains, eksplanasi ilmiah hipnotif berkembang mengikuti pola Deduktif-Nomologis. Dalam hal ini, deduksi hipnotis telah berkembang melalui proses sains dari system kepercayaan (belief system) dan cenderung bersifat dianggap intuitif pada masa jauh sebelum masehi. Lebih lanjut, hipnotis secara empiris terbukti efektif berdasarkan hasil-hasil studi-studi eksperimentasi multidisiplin baik skala laboratorium maupun skala lapangan. Dengan demikian, keilmiahan hipnotis dapat didukung dari dua paradigm kebenaran yaitu paradigm naturalistic, paradigm positivistic dan satu teori kebenaran yaitu teori pragmatism.

\section{Daftar Pustaka}

Ellias (2009). Hipnosis \& Hipnoterapi, Transpersonal/NLP. Jogjakarta: Pustaka Pelajar.

Fachry, HA. (2008). the Real Art of Hipnosis: Kolaborasi Seni Hipnosis Timur-Barat. Jakarta: Gagas Media

Firman, H. (2018). Filsafat Sains. Program Studi Pendidikan IPA. Sekolah Pasca Sarjana UPI

Gunawan, AW (2008) the Secret of Mindset Jakarta: Gramedia Pustaka Utama.

Hakim, A. (2010). Hipnoterapi: Cara Tepat \&Cepat Mengatasi Stress, Fobia, Trauma, \&Gangguan Mental Lainnya. Jakarta: Transmedia Pustaka

Hastuti \& Ayumsari (2015) Pengaruh Terapi Hipnotis Lima Jari untuk Menurunkan Kecemasan pada Mahasiswa yang sedang Menyusun Skripsi di Stikes Muhammadiyah Klaten. Motorik, Vol.10 Nomor 21, Agustus 2015

Hoeft F.,Gabrieli JDE., Whitfield-Gabrieli S., Haas BW, Bammer R, Menon V., Spiegel D. (2012). Functional Brain Basis of Hypnotizability. Arch Gen Psychiatry/ Vol 69 (No. 10), Oct 2012.

Huber A, Lui F, Duzzi D, Pagnoni G, Porro CA. (2014) Structural and Functional Cerebral Correlates of Hypnotic Suggestibility. PLoS ONE 9(3): $e 93187$. doi:10.1371/journal.pone.0093187

Hutapea, B (2011). Menggeser Kesadaran Sebagai Pusat Manusia Yang Mutlak dan Otonom: Subjek Freudian Dalam Kritik Terhadap Filsafat Subjektivitas. Psikobuana 2011, Vol. 3, No. 2, 141-148

IBH (Indonesian Board of Hipnotherapi) (2002). Buku Panduan Resmi Pelatihan Hipnosis. www.ibhcenter.org, diakses Maret 2018.

Kahija, Y (2007) Hipnotherapi: Prinsip-prinsip Dasar Praktek Psikotherapi. Jakarta: Gramedia Pustaka Utama.

Kaplan \& Sadock. (2004) Sinopsis Psikiatri: IImu Pengetahuan Perilaku Psikiatri Klinis, Edisi ketujuh, jilid satu, hal 430.

Kroger (2008) Clinical \& Eksperimental Hypnosis, Revised Second Edition. Lippincott Williams \& Wilkins.

Lubis, AY. (2016). Filsafat IImu Klasik hingga Kontemporer. Jakarta: PT RajaGrafindo Persada.

Luders, E, Steinmetz, H \& Juncke, L. (2002). Brain size and grey matter volume in the healthy human brain. Cognitive Neuroscience and Neuropsychology. Vol 13 No 173 December 2002

Oakley, DA.,\& Halligan PW. (2013).Hypnotic Suggestion: Opportunities for Cognitive Neuroscience. Nat Rev Neurosci. 2013. Aug;14(8):565-76. DOI: 10.1038/nrn3538. Epub 2013 Jul 17.

Prihantanto (2008). Lebih dekat \& sehat dengan hypnotherapy. Artikel. Diakses dari https://anzdoc.com/, 24 Maret 2018

Paul, LK, Brown, WS, Adolphs R, Tyszka JM, Richards, LJ, Mukherjee, P. \& Sherr, EH (2014). Agenesis of the corpus callosum: genetic, developmental and functional aspects of connectivity. Nat Rev Neurosci. 2007;8:287-299.

Putra, YP (2010) Hipnosis Ericksonian dan Metode Pengembangan Pikiran Lainnya. Jakarta: Elex Media Komputindo

Raven, PH \& Johnson, GB. (2009). Biology:10th Edition. USA: Wahington University

Reece, J. B., Urry, L. A., Cain, M. L. 1., Wasserman, S. A., Minorsky, P. V., Jackson, R., \& Campbell, N. A. (2014). Campbell biology (Tenth edition.). Boston: Pearson.

Rusli, SI \& Wijaya, JA. (2009) the Secret of Hypnosis. Jakarta: Penebar Plus 
Spiegel D (1985) The Use Of Hypnosis In Controlling Cancer Pain. CA-A Cancer Journal for Clinician Vol 35: 4, pp $221-30$

Sudarmin (2016) Pengantar Filsafat Pendidikan dan Pemikir Sains. Semarang: CV. Swadaya Manunggal

Zillmer, E., Spiers, M., \& Culbertson, W. (2008). Principles of Neuropsychology. USA: Thomson Higher Education.

Zulkaida I, Dewi, MP\&Prabowo, H (2005) Metode Mengajar Dengan Menstimulasi Otak Kiri Dan Otak Kanan. Proceeding. Seminar Nasional PESA T 2005 Auditorium Universitas Gunadanna, Jakarta. 